\title{
Jimmy Steele: 'It's not as if we are going to run out of work'
}

Please send any ideas for feature articles for consideration to:

Ruth Doherty,

Managing Editor,

British Dental Journal,

The Macmillan Building,

4-6 Crinan Street,

London,

N1 9XW

Email: r.doherty@nature.com

BDJ Managing Editor, Ruth Doherty, caught up with Jimmy Steele at the British Dental Conference and Exhibition held in Manchester in April earlier this year.

\section{With the prevalence of caries apparently in decline - what is future for dentistry?}

The future for dentistry is pretty good. There is a risk that we think caries is declining so there's going to be nothing for us to do as dentists - that's rubbish! Not least because there is an entire population of people over 45 who need their teeth maintained but also as there is a need for dentists to be involved in promoting really good health.

Fundamentally contributing to preventing disease is more satisfying than being an amalgam monkey: drilling, filling and being on the treadmill. There are changing demands all the time and people constantly want different treatments. What we all do will change but it's not as if we are going to run out of work. That is simply not going to happen in the immediate future.

\section{Where did your interest in epidemiology of dental health stem from?}

I came to Newcastle in 1989 to take up a lectureship position and at that time, even though I was starting out as an academic, I had no real research experience. That was normal then, unlike these days where people already have a $\mathrm{PhD}$ and some research experience when awarded lectureship positions. An opportunity arose to study the changing demographic - older people and

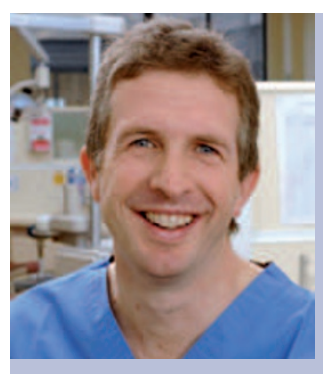

Professor Jimmy Steele CBE is Head of Dental Sciences at Newcastle University and also practising as a consultant in restorative dentistry with Newcastle Acute Hospitals Trust. He qualified with a BDS from the University of Dundee in 1985 and after four years in NHS hospital dentistry he moved to Newcastle University to take up a position as a lecturer. He then completed his PhD in 1994 and became a senior lecturer/honourary consultant at Newcastle in 2003.

Jimmy is one of the senior members of the consortium which worked with the Office for National Statistics on the 1998 and 2009 Adult Dental Health Surveys and the 2003 Children's Dental Health Survey. He led the Review of NHS dental services in England for the Government in 2009 and the resulting report prompted him to be dubbed the 'architect of the future of NHS dentistry'. Jimmy is currently working with the Department of Health to implement the report recommendations as part of the new NHS dental contract and pilots in England. In addition to this, he is also the current National Oral and Dental Speciality Lead for the National Institute for Health Research (NIHR) and on two NIHR fellowship panels.

their needs. At that stage the premise of the study was based on projections that there were going to be more older people, but actually as I started investigating this for dentistry that aspect wasn't the most important thing; the changes in oral health in different generations was much more important.

Though I wouldn't really describe myself as an epidemiologist, I have been involved in quite a lot of epidemiology and find it interesting. If you speak to anybody with a background in research there will be something that they know an awful lot about and feel comfortable with. For me that subject is big surveys of the population. I know how they work and I understand them. When you do that sort of work for the first time, you think it's about the questions but you're usually asking far too many. It's only when you start to write things up and make sense of it do you realise that you're swamped with information. What you really need is valid information for what is most important. A lot of people don't realise this - it's a skill in itself.

\section{Are patients using the internet to research treatment options?}

Definitely, there is a lot of information about treatments on the internet. Some of it is good and some of it is very bad. Unfortunately there's not much authoritative information and in a well-functioning marketplace, and dentistry is a market, one of the basic conditions is the availability of high quality information so people can make decisions. The dentist will always know more than the patient which makes the 
'market of healthcare' very difficult. The patients don't have five years of training. The democratisation of information is fine but there have to be signposts so people know what information they can trust and to help them to use it properly. These days a lot of my time as a consultant in restorative dentistry is spent as an impartial advisor trying to make sense of various complicated treatment options for the patient.

\section{To what extent will periodontal disease require treatment by dentists?}

\section{The data from the 2009 Adult Dental} Health Survey ${ }^{1}$ are absolutely fascinating around periodontal disease because the prevalence of moderate disease has reduced (classed for the purpose of that survey as any sextant with a pocket of $4 \mathrm{~mm}$ or more) but severe disease hasn't. First of all, we need to find out why this is the case but providing good periodontal services going forward will certainly be very important.

However, another significant consideration that people don't often think about, is that we will have to manage moderate disease. If people are now going to live and keep their teeth to the age of a hundred even slow incremental loss of periodontal attachment will catch up with them eventually. So being preventive in our approach to periodontal disease, showing good hygiene etc, is a positive thing. People's oral hygiene in this country has improved immeasurably which can only be good.

\section{What achievement or undertaking have you been most proud of?}

In my spare time I go and look at birds. I've found a few very rare birds and that gives a great instant buzz; for example, I have found Britain's second black-faced bunting!

Professionally, I enjoyed doing the review [Steele review of NHS services in England ${ }^{2}$ ] and found it really interesting. I also contributed to a book on occlusion a few years ago and I enjoyed doing that. I think it's quite a good book and though I don't take much credit for it, as I didn't do the important bits, I'm actually quietly proud of it.

Ask me again in another two decades!

\section{What do you feel is the most important attribute for a clinical dentist?}

When I first started I would have said 'a good pair of hands' but now that I have spent many years teaching technical skills to students I think I have a much better understanding of what is required. For the vast majority you can actually teach the technical skills and some of the people with 'good hands' don't become good dentists, so I've changed my position.

When we interview in Newcastle I'm looking for people who are interesting, ethical, express an opinion and can defend it. As for attributes that people develop over time: I want them to be able to take responsibility, to act professionally and to put health first. There is a constant tension between the business of dentistry, which is terribly important, but also your role as a professional. It can be very hard to balance the two. An ability to make sure you get the balance the right way round is very important. The best and most successful dentists I know are, first and foremost, really good healthcare professionals. They may drive a fast car but they also realise what's vital and put that first. It's also increasingly important to be good with people, prepared to listen and understand.

\section{What changes do you envisage in dental education over the next ten years?}

Well, we would stop teaching technical skills at our peril as they are really important. However, the way we teach technical skills is changing. We must ask about the nature of the skills that we are teaching. It's not necessarily just about what is in the hands but about what is in the head. It's not about doing and copying. It's about attitudes, attention to detail, knowing when to stop and when to take advice. We must think more about evidence and there is a lot of information out there in terms of evidence-based dentistry that we can use.

One of my colleagues in Newcastle is talking about getting historians involved in dental education and I think that's a really good idea. You might ask what that has got to do with dentistry; surely it's more about science subjects? Well it isn't! When a clinician takes a patient history the skills used to make sense of the information are the same as those that a historian would use. You look at sources, you have a direct contemporary source and a secondary source from a referral letter or what a carer might be saying, you have objective evidence in terms of radiographs and examination and you have to balance all this together to make sense of it. It's not just a metric - if it was a metric you could just feed it into a computer and get an answer. The technical stuff is important, being able to evaluate scientific evidence is important but so is being able to evaluate softer types of evidence.

We are pretty good at what we do but we are a long way from perfect. We need to look at the people we are recruiting and whether we are asking for the right sort of things. For any clinical discipline you definitely need biology, there is no question about that, but we also need some humanities in there and all sorts of other things. We are in danger of being a bit too narrow in terms of how we think about it.

\section{How do you feel the NHS dental contract pilots are progressing?}

There are three subtly different models being tested and people shouldn't assume that one of these models is going to be the end point. It's not. The three models are being tested so that the Department of Health can take learning from all of them and come to a sensible conclusion.

I think they are going reasonably well and the feedback has generally been quite good. There have been more than a few problems with the IT but there is time to get that right. The oral health assessment is a big change for people and that might need modification which is fine. Of course, there will be issues of time and implementation. The pilots are all very well but the really hard bit will be implementing them and motivating people to buy into the implementation. It's difficult to do and I think everybody recognises this fact but that's not a reason for not doing something that is necessary for the health of our population, the taxpayer, and above all the dentists. There is still some really hard work to do; I have no illusions about 
that. One of things we have to think about very carefully is the transition stage as the system cannot just change overnight - this would be too difficult.

\section{You are a member of two NIHR Fellowship panels - what is your advice to a dental researcher applying for funding?}

I have to say it's really interesting being on these panels. It is great to see really bright dental academics coming through, competing with the best that medicine has to offer and winning fellowships. I would warn people that though there are funding opportunities available, they are really hard to get. You must put the time in and work carefully on the idea you want to take forward, ask for the best advice, recognise your limitations and address them. I think that clinical dental research in particular has the potential to be in a good place. I've seen a change in just the last few years in terms of an increase in opportunities and money going into clinical research. There are probably at least four really big multi-million pound trials running at the moment across practices in the UK.

Practice-based research is another way to become involved in dental research. The data that dentists collect routinely and the involvement of their practices in trials gives them an opportunity to diversify.

What I'm really keen to see is that we start to identify the questions that are really big and we are fearless about putting in big applications. The NIHR was set up six years ago and it operates with clinical bias. It likes to pick up on some of the problems that pharma are not going to solve and dentistry falls right into that area. We must be cooperative and bold. Most research is now done across many dental schools and is highly professional which is fantastic. It's not just small studies done in your spare time as it was when I started out 23 years ago. Dentistry research is upping the professional anti.

\section{What is the biggest challenge in putting something like the Adult Dental Health Survey together?}

The biggest challenge is getting people to take part! The response rates are a nightmare. Forty years ago if you knocked on someone's door and asked them to take part in a survey for Her Majesty's Government they would say 'yes sir, of course'. Now we knock on a door and there's a fair chance of being told where to go! There seems to be a suspicion of government in today's world. However, as patients of the NHS, within reason, I think we've got an obligation to put something back into it. That's not the rhetoric you currently see out there. It would be nice to see that changing but I don't see it happening quickly.

\section{When you're not working what do you like do?}

Regular bird-watching. I've got two patches in the North East coast of England where I go birding religiously. I also cook fish and forage for mushrooms. I'm thinking of getting some lobster creels. I like being a hunter-gatherer.

\section{Jimmy's tips for buying the freshest fish:}

Get to know your fishmonger. (Never believe what they say!)

1. Look at the eyes - they should be clear

2. Look at the gills - they should be red or pink
3. Touch the fish, pick it up. In flat fish you should turn them over to check for bruising

4. Get the fish from a supplier where you know what the source has been so you can make sure they are freshly caught

5. The best sign of all is if you pick the fish up by the tail and it doesn't move due to rigor mortis - then it's fresh!

\section{If you were prime minister,} what would you use the power to achieve?

I would try and develop a sensible approach to our natural environment. I am quite worried by how detached we all are, children in particular, from the natural world. It is important to make sure that all children have an understanding of the science of the natural environment. It is what sustains us.

I would also push to get people with a scientific background into parliament. We live in a world of science but there are few MPs with a science background or understanding. I believe this will cost us in the long term. If the decision-makers don't understand scientific principles we have no chance. A parliament with a whole range of skills is very important for the future.

1. Steele J, O'Sullivan I. Executive summary: adult dental health survey 2009. Leeds: The Health and Social Care Information Centre, 2011. http://www.ic.nhs.uk/webfiles/publications/007_Primary_Care/Dentistry/dentalsurvey09/ AdultDentalHealthSurvey_2009_Theme5_ Preventivebehaviourandriskstooralhealth.pdf (accessed 2 August 2012).

2. Steele J, Rooney E, Clark J, Wilson T. An independent review of NHS dental services in England. London: Department of Health, 2009. http://www.dh.gov. uk/en/Publicationsandstatistics/Publications/ PublicationsPolicyandGuidance/DH_101137 (accessed 2 August 2012). 